\section{INTERROGATION/ POLICE INTERVIEW:
MYTH, REALITIES AND \\ INTERROGATION/ POLICE INTERVIEW:
MYTH, REALITIES AND CHALLENGES}

CHALLENGES

\section{ABSTRACT}

The police interview or interrogation, one of the major tools of criminal investigation is no longer confined to pre-trial investigations, but transcends to forensic labs and the Court rooms of learned Judges. The investigators, forensic experts and prosecutors need to act in synergy to improve the performance of the Criminal justice system. In this backdrop, the article examines the subject of interrogation on a broad canvass of constitutional and legal parameters, police professionalism and evidentiary value and human- civil rights issues. It underlines the need of the lead actors of the criminal justice system properly understanding certain myths and challenges connected with interrogation so that they can better appreciate the evidence or inputs generated through interrogation, at professional plane. It also discusses as how the science and technology have become a major aid in

\footnotetext{
a. PKV Thomas, B.sC LLB, had around four decades of distinguished service in Intelligence Bureau. He served in different parts of India including the insurgency affected areas of the North East and the Left Wing Extremist infested States. For his outstanding contributions to the Bureau, he was decorated with President's Police Medal for distinguished service (2008); Indian Police Medal for meritorious service (1996) and Internal Security Medal (2000) for outstanding operational achievements in insurgency/ extremist affected areas. The National Police Academy, Hyderabad awarded him Police Fellowship in 1997 for undertaking a research project on Policing and Human rights. He won the prestigious Prime Ministers' Silver Cup Essay competition conducted by National Police Academy on six times. He has authored three books: Human Rights, Terrorism and Policing in India (1999); The Policing in 21st centurymyth, realities and challenges (2012) and Left Wing Extremism \&Human Rights (2014).
}

KV Thomas ${ }^{a}$

tomskara@yahoo.co.in Fecha de recepción: 22 de mayo de 2017 Fecha de revisión: 26 de junio de 2017 Fecha de aceptación: 15 de agosto de 2017
MISIÓN JURÍDICA

Revista de Derecho y Ciencias Sociales

Bogotá, D.C. (Colombia)

Colaboraciones Especiales

Núm. 13 Año 2017

Julio - Diciembre, pp. 423 - 429

ISSN 1794-600X 
overcoming many bottlenecks in the traditional methods of interrogation or police interview.

\section{KEY WORDS}

Interrogation, Criminal Justice Reforms, High Value Detainee Interrogation Group (HIG), Reid and Kinesics models, Michael Crowe case, scientific tools to interrogation.

\section{DEVELOPMENT OF THE RESEARCH}

The edifice of criminal justice system in any country rests on three main pillars namely investigation agencies which conduct pre-trial investigation of offences, prosecution and defense lawyers who assist the court to determine the truth at trial stage and the presiding officer or Judge who gives the verdict declaring the accused either guilty or innocent. The better synergy among these three vital entities is crucial for the smooth and effective functioning of the criminal justice system.

In this regard, certain pertinent questions come to our mind. Whether the personnel of these three crucial organs of the criminal justice system are equipped with adequate skills, knowledge, professionalism or expertise to effectively perform their chartered duties or tasks? Whether the existing mechanisms or pre-entry training schemes are adequate to equip them with the required skills to meet the new challenges and complexities in the criminal justice system? If not, what structural or organizational changes or innovative mechanisms should be initiated to overcome the bottlenecks in the criminal justice system? Such questions are more significant in the case of developing countries like India where the criminal justice system is under considerable stress and strain due to a confluence of factors.

Naturally, such issues do attract the attention of policy-makers or those at the helm of affairs of these institutions. The US Congress and the House of Commons in UK periodically review the performance of their criminal justice system by appointing Special Committees whose recommendations were recommended from time to time. In India, Justice VS Malimath Committee on $2003^{1}$ has made exhaustive study on these aspects and made a number of recommendations to revamp the criminal Justice system. The Committee highlighted that the investigators, forensic experts and prosecutors should act in proper coordination so that the performance of the Criminal justice system can be improved. In fact, all these Committees have identified the need of various structural and organizational mechanisms to improve the professional skills and expertise of the personnel to cope with the new challenges.

Basically, the proper understanding of the modern science of criminology in all its bearings is a must for the above three categories of personnel. While it is necessary to know the bio-psychosocial theories regarding the causes of criminal behavior, it is of greater importance to master the advancements in the field of Forensic Science or Scientific criminology to bring offenders to justice.

The spectacular advancements in the field of cybernetics and cyber-forensics have virtually revolutionized the criminal investigations. The police interview or interrogation has now become a major component of investigation. Interrogation no longer is confined to pre-trial investigations but transcends to forensic labs and the Court rooms of learned Judges. No doubt, police investigators, lawyer community and judicial officers need to improve and update their knowledge e in those spheres to do full justice to their profession. There is flood gate of literature on the subject. But, our endeavor is to examine the subject of interrogation on a broad canvass of constitutional and legal parameters, police professionalism and evidentiary value and human- civil rights issues.

The interrogation is the act of systematic questioning of an accused or suspect to elicit true statement. The British criminologists described interrogation as an art or science of making suspects speak truthfully. However, there are different perceptions on the question of designating interrogation as a science. One argument is that interrogation unlike other areas of science has not been developed on the basis of any proven hypothesis arrived through tests or experiments. On the other hand, these techniques have been evolved on the basis of the experiences and observations of their practitioners without any scientific basis.

The aim of interrogation or police interview is to get the most useful information about a crime or offender or an organization from a detainee in a humane and lawful manner with sufficient oversight by trained investigators or interrogators. This covers a wide spectrum of evidence or data such as the actual occurrence of 
event, facts and circumstances, persons involved, their antecedents, links with other crimes or criminals, future plans, recovery/discovery of items, evidence for prosecution and confession.

A properly planned and executed interrogation by professionally competent interrogators can unearth a goldmine of useful information on organized crimes, Counter-intelligence, economic offences and of course, traditional crimes or offenses like murder, rape, theft etc. Perhaps, the best example in the recent past was the High Value Detainee Interrogation Group (HIG) ${ }^{2}$ constituted by US president in June 2009 after 9/11 terror attack in the US in 2001. The main task of this body comprising personnel of Central Intelligence Agency (CIA), Federal Bureau of Investigation (FBI), the US Department of Defense and other Specialist groups was to generate actionable intelligence on any imminent terror strike or plots, through the systematic interrogation of detained terror suspects. In fact, US take much credit for the non-occurrence of post 9/11 terror strikes in their country for such drastic measures adopted by the Homeland Security and their intelligence establishments.

But such interrogation techniques used by many countries in their organized fight against global terrorism, sometimes evoke constitutional and legal issues and violation of international conventions or protocols. The International Covenant for Civil and Political Rights (1966), Geneva Conventions -III\&IV and Additional Protocol-I have specific provisions against torture, cruelty or inhuman/degrading treatment of prisoners of war, civilians or unlawful combatants subjected to detention and interrogation. The International humanitarian law, International Human Rights law and the domestic laws of many countries have similar protective clauses to safeguard the rights and privileges of persons in custody or detention.

The Miranda clause requirement set by the US Supreme Court in Miranda vs. Arizona ${ }^{3}$ in 1966 is described by many as a 'Magna Carta' in safeguarding the rights of citizens being subjected to interrogation. The above clause stipulated that prior to the time of arrest or interrogation of a person suspected of crime, he or she has the right to remain silent; the right to legal counsel and the right to be told that anything he or she says will used in court against him/her. The Miranda clause finds place in the constitution and legal framework of many countries in one way or other. For example, in India, the Right to silence is a fundamental right guaranteed to the citizens under Article 20(3) of the Constitution which says that no person accused of any offence shall be compelled to be a witness against himself.

Ironically many of these Covenants, Protocols, laws and regulations have been relegated to the background when overenthusiastic political regimes give a free hand to investigators and interrogators to deal with grave issues like terrorism. Many Human Rights groups highlight 'Guantanamo Bay' as the best example holding that the terror- suspects were subjected to inhuman torture and cruelty in the above interrogation center run by the US. Their main criticism was that the special interrogation techniques approved by US Defense Secretary in April 2003 under the Special Training Program called 'SERE' (Survival, Evasion, Resistance and Escape) violated the basic rights of suspects during the interrogation. Some of these techniques such as total isolation sleep deprivation, forced nudity, Sexual humiliation and Water -boarding were reminiscent of US soldiers' crude interrogation methods against Vietnamese soldiers and prisoners.

All the above techniques one way or other violate the UN conventions especially the Clauses of Geneva Convention to which USA is a signatory. In fact, after 9/11, the US had taken a stand that Geneva Convention Protocol or clauses need not be followed in letter and spirit in the case of terror suspects especially those belonging to Al Qaida and Taliban. Thus, unlawful techniques of interrogation went unabated in Guantanamo bay of Cuba, Abu Gharaib of Iraq, Bagaram of Afghanistan and the network of CIA 'black sites' in different countries. The reality is that when US defiantly and boldly pursue such techniques of interrogation, many other countries clandestinely adopt such unlawful techniques in interrogations. This leads to steady increase of human rights violations in different countries, which have evoked wide spread reaction from the Amnesty International and other Human Rights NGOs, world over.

At the same time, every sovereign State is duty bound to protect the lives and properties of citizens for which crime control through lawful means is an essential aspect. Police is the most visible instrumentality of the State in 
crime control mechanisms. The Criminal law and procedures empower any investigator to interrogate suspects involved in the commission of crime. But, all police personnel need not be successful interrogators. An ideal interrogator should have an impressive personality, blessed with a number of personal and professional traits such as patience, compassion, determination, confidence, alertness, good memory, gift of gab, sound knowledge of various subjects, decent mannerisms, kindness, frankness and sincerity and above all the ability to win over the respect of the suspect. Hans Gross ${ }^{4}$ had rightly summarized these qualities as; 'He who knows man; who is gifted with memory and presence of mind; who takes pleasure in his work and zealously abandon himself to it; who is always scrupulously bound by the rules laid down in law and who sees always in the accused a fallen brother or one who is wrongfully suspected, he will question well'

The successful interrogators develop many of those professional traits through their long experience in this field. Thus, professionallyconscious Police and Security organizations have formed separate cells or branches exclusively for interrogation tasks. Over the years, by interrogating a wide variety of suspects such as terrorists/extremists, espionage agents (external and internal), secessionists and insurgents, economic offenders, communalists and fundamentalists, hardened criminals and other offenders of serious crimes, the personnel of such branches develop necessary strategies, skills, sound knowledge and understanding on human psychology and weaknesses that make them the best professional interrogators.

However, even such professionally competent and experienced interrogators deviate from the basic canons of interrogation at the instance of the ruling establishment or to fulfill the whims and fancies of the top brass or the agency in charge of the investigation or interrogation. Sometimes, the interrogators act on their specific orders 'to break the suspect psychologically or to break him or her physically so as to get the initial findings established at any cost'. Majority of the interrogators conscious of their professional or career interests seldom resist such dictates! Influenced by such preconceived approach, interrogators adopt unlawful means including 'third degree methods' to extract false confession from the suspect virtually defeating the due process of law in the investigation process.

Lack of professionalism or proper planning are other major bottlenecks that defeat the very purpose of interrogation. The formation of adhoc or quick-fix interrogation teams to meet exigencies or to question an array of suspects is a common practice in many agencies. Sometimes, public rhetoric or media-trial of sensational crimes or offenders forces the authorities to make such hotchpotch arrangements. From my practical experience, I can safely state that such exercises seldom serve any purpose to adduce evidence in the investigations or collect useful intelligence in sensitive operations. For example, during crucial counter-insurgency operation in one of the North Eastern states of India during early 1990s, dozens of security/intelligence personnel who served in that state some decades ago were air-lifted from various destinations and assigned with the task of 'interrogating' the suspected ultras of a dreaded insurgent outfit of recent origin . Anyone can well imagine the actionable or useful intelligence or leads generated by these 'so called interrogators' who treated the entire exercise as a picnic to a troubleprone state at the cost of national exchequer! Same was the case with 'interrogators' who were totally ignorant of space science or technology but entrusted with task of questioning internationally renowned space scientists implicated in an infamous espionage case!

No doubt, such human factors or errors cast shadow on the authenticity of inputs or evidence adduced by the investigators through interrogation. This, to a great extent, can be overcome through corrective mechanisms at organizational or personnel level. But, the more serious challenge is the built-in weakness in the traditional methods of interrogation holistically practiced by investigation agencies from time immemorial. In this connection, let us examine two universally accepted models of police interview or interrogation namely, Reid and Kinesics.

In the Reid technique, the emphasis is to extract confession or admission of guilt from a suspect through a series (nine) of steps. Those inter-alia include: direct confrontation urging the suspect to explain why the offense took place; shifting the blame away from the suspect to some other person or circumstance to build confidence on him to speak truth; discouraging the suspect from denying the guilt; trying to use suspect's 
explanation to move towards the confession; reinforcing sincerity to ensure that suspect is receptive; posing alternative questions giving two choices- guilt or otherwise and finally leading to the suspect's confession or admission of guilt that is recorded as evidence.

The Kinesic interviewing places more reliance on the subject's word choice and phrasing in respect of questions posed to him or her. This model had also formulated an elaborate deception- detection technique based on body movement, Facial expressions, possible physical characteristics of Head, Eyes, Hands and legs, besides physiological symptoms and voice variation while a suspect is on interview process.

On a closer analysis, the above models of interrogations are based on the complex interrelations between human mind and body that are manifested through distinct physical and metabolic changes under special circumstances or situations. The underlying principle is that the suspect or the accused under stress or strain created through systematic questioning would exhibit distinct physical, psychological or verbal behaviors, based on which the interrogators can arrive at conclusions on their involvement or otherwise in a specific crime or offence. In William Sargant's ${ }^{5}$ words; "The stress that they (interrogators) put the subject under causes distinct and predictable physiological effects that result in the subject losing his/her previous sets of beliefs'. This change in belief ultimately leads to confession.

Considering the complexities of the human mind as unraveled by psychologists and psycho -analysts like Sigmund Freud ${ }^{6}$, Dr. Alexis Carrel $^{7}$ etc. in the last century, one pertinent question is on the reliability or authenticity of such changes or the confessions by suspects under stress. How far such confessions can be taken for granted in the case of hardened criminals or highly indoctrinated terrorists of 'Fidayeens' (suicide squads) prepared to sacrifice their lives for the cause for which they fight?

In the backdrop of such questions, the Reid and Kinesic models of police interview/ interrogation had come under major criticism for their over-emphasis on the confession of suspects. The sensational murder case of Stephanie Crowe of Escondido, California in 1998 and the proven false confession of two juveniles during interrogation evoked wide spread public debate and awareness on the problematic police interrogation techniques leading to false confession and miscarriage of justice. In the above case, 14 year old Michael Crowe, the brother of the victim who was initially suspected in the murder succumbed to the pressure and falsely confessed after nine hours of intense interrogation including the infallible Computer Voice Stress Analyzer test. Joshua Treadway, Michael's friend and suspected co-perpetrator in the crime was interrogated for about 22 hours. He too had confessed on the lines of Michael. Fortunately for Michael and Joshua, their innocence was established when Stephanie's blood was discovered on the sweatshirt of a homeless drifter, Richard Tuite, who was subsequently tried and convicted. The inadequacy of legal mechanisms to avert such tragedies also came under sharp criticism. These developments paved the way for extensive research on various interrogation techniques.

One of the main themes of these researches was the reliability of the detection or deception by suspects during interrogations. The researchers found that behavior or response styles of suspect during interrogation cannot be fully relied upon in identifying the truth from deception. It was also established that interrogators who depend on non-verbal or linguistic clues as indicators are prone to error. Another factor for false confession was investigator's bias or 'tunnel vision'. This is a common phenomenon in criminal justice system in which the lead actors such as investigators, prosecutors, judges and defense lawyers focus on a suspect; select and filter the evidence that will build a case for conviction, while ignoring or suppressing evidence that points away from the guilt. Thus, in many cases interrogators easily overlook or dismiss any statement or disclosure by the suspect that is inconsistent with the chosen theory, attributing them as irrelevant, unreliable or incredible.

Thus in order to minimize the miscarriage of justice, the future generation of police investigators, lawyers and judicial officers should be aware of certain myths and misconceptions about police interrogation. The myth number one is the argument by section of police leaders that police interrogation is a science and hence the evidence so adduced through this process should be taken for granted by the Judiciary. Time and again, it is proved that various interrogation techniques are not based on any hypothesis or 
proven experiments as in the case of various branches of science.

The second myth is that the false confessions are almost nil or extremely rare in police interview or interrogation. This is found to be factually incorrect as proved by a number of cases and studies. Perhaps, the best example is the Stephanie Crowe case.

Another misconception is that vulnerable individuals are prone to false confession. Though there is general tendency of Juveniles and youth easily yielding to false confessions, it is incorrect to make inference that the vulnerable persons are easily prone to confessions. What matters more in the case of confession by suspects belonging to higher strata of the society are the nature of interrogation techniques, bias approach of interrogators and their eagerness to extract confession from the suspect at any cost? The third degree methods also play a crucial role in such confessions. There were many instances when senior scientists and bureaucrats, unable to withstand the humiliation and mental torture by the interrogators volunteered to make any sort of confession where as their drivers or houseservants stood to their ground for days without yielding to the interrogation techniques. Another myth projected by police a leader in particular is that the study of police interrogation or false confessions are in infant stage and as such no conclusive findings could be arrived at on such matters.

The argument that Juries do not want experttestimony is contrary to actual facts. Instead they attach considerable significance to the scientific and Forensic evidence or data brought before them during the trial. Influenced by public uproar or media trial, some of them handle such evidence indifferently or callously leading to the gross miscarriage of justice. Despite aberrations, Indian judicial system has enough check and balances to avert such bottlenecks, as pieces of technical or electronically generated evidence are never taken as conclusive, but only as corroborative evidence.

That doesn't mean that investigators or interrogators need not look for scientific tools or methods in criminal investigations. Essentially, they should. With the advancement of science and technology, such tools have become inevitable and crucial aids to any successful investigator. For example, in the field of interrogation, the Lie detector or the Polygraph test, the P300 or the Brain Mapping test and the Narco-analysis or the Truth Serum test have been widely used for extracting confessions or ascertaining truth. These psychoanalytical tests are also used to interpret the behavior of criminals or suspects for corroborating the findings of investigators.

In fact, medical research and neurological studies paved the way for such innovations in the criminal investigation field. For example, the researches by Robert House, a Dallas Texas physician on the effect of scopolamine during child birth led to the genesis of Narco- analysis. Scopolamine was known to produce sedation and drowsiness, confusion and disorientation, incoordination and amnesia for events experienced during intoxication. Thus, he concluded that a patient under the influence of scopolamine temporarily loses the power to think or reason and thus cannot create a lie. The above test was first introduced in 1936 to induce a suspect under the influence of the drug so that he talks freely without trying to manipulate his answers.

The Narco- test is now conducted by mixing 3 grams of Sodium Pentothal or Sodium Amytal dissolved in $3000 \mathrm{ml}$ of distilled water. Depending on the person's sex, age, health and physical condition, this mixture is administered intravenously along with $10 \%$ of dextrose over a period of 3 hours with the help of an anesthetist. The effect of the bio-molecules on the bio-activity of an individual is evident as the drug depresses the central nervous system; lowers blood pressure and slows the heart rate putting the subject into a hypnotic trance resulting in a lack of inhibition. The subject is then interrogated by the investigating agencies in the presence of the doctors. The revelations made during this stage are recorded both in video and audio cassettes. The report prepared by the experts is used in the process of collecting evidence. The consent of the person is required to conduct the test.

The Polygraph or Lie Detector Test is based on an assumption that there is an interaction between the mind and body. The signs or effects of this interaction are monitored by various components or the sensors of a polygraph machine attached to the body of the suspect subjected to interrogation. A clinical or criminal psychologist prepares a set of test questions depending upon the relevant information about the case provided by the investigating officer, such as the criminal charges against the suspect and statements made by him. 
He is questioned and the responses are measured. Lying by a suspect is accompanied by specific perceptible physiological and behavioral changes which are recorded by the sensors. The responses so recorded in the form of a graph are analyzed by the experts/ investigators.

P300 or the Brain Mapping test is one of the latest tools used by interrogators. This test was developed and patented in 1995 by neurologist Dr. Lawrence A. Farwell, Director and Chief Scientist of 'Brain Wave Science'. In this method commonly known as 'Brain-wave finger printing' the accused or the suspect is first interviewed and interrogated to find out whether he is concealing any information. After attaching sensors to his head, he will be seated before a computer monitor. He is then shown certain images or made to hear certain sounds. The sensors monitor electrical activity in the brain and register P300 waves, which are generated only if the subject has connection with the stimulus i.e. picture or sound. Dr. Farwell has published that a MERMER (Memory and Encoding Related Multifaceted Electro Encephalographic Response) is initiated

(Endnotes) 1.http://www.mha.nic.in/hindi/sites/upload_files/mhahindi/
files/pdf/criminal_justice_system.pdf last accessed $o$ a October 25, 2016

2. The High-Value Detainee Interrogation Group, or the HIG, is a cooperative effort between the FBI, the CIA, the Department of Defense, and other government agencies. Frazier Thompson, IV was the first Director.

3. In Miranda v. Arizona (1966), the Supreme Court ruled that detained criminal suspects, prior to police questioning, must be informed of their constitutional right to an attorney and against self-incrimination.

4. Hans Gustav Adolf Gross was an Austrian criminal jurist and an examining magistrate. He is believed to be the in the accused when his brain recognizes noteworthy information pertaining to the crime. These stimuli are called the 'target stimuli'.

Just like innovations in the field of scientific or forensic tools for interrogation, criminal investigation agencies world over are experimenting with new techniques of interrogation. The biggest challenge before the agencies is as how this tool can be effectively used to generate inputs that can avert terror strikes or other organized crimes, while upholding the due process of law. Another area of concern is the false confessions by the accused/suspects which lead to miscarriage of justice. Taking such factors into account, many countries/ agencies have formulated new interrogation standards which inter-alia include: minimizing the use of psychologically manipulative techniques; video-recording of custodial interrogations; better training for improving professionalism of interrogators and special precautionary measures in respect of the interrogation of vulnerable sections. Naturally, such measures will give more reliability to the evidence generated by investigators through interrogation. creator of the field of criminalistics and is to this day seen as the father of Criminal investigations....

5. William Walters Sargant was a British psychiatrist who is remembered for the evangelical zeal with which he promoted treatments such as psychosurgery, deep sleep treatment, electroconvulsive therapy and insulin shock therapy. His most popular work is "Battle for the mind"

6. Sigmund Freud was an Austrian neurologist and the founder of psychoanalysis, a clinical method for treating psychopathology through dialogue between a patient and a psychoanalyst

7. Alexis Carrel was a French surgeon and biologist who was awarded the Nobel Prize in Physiology or Medicine in 1912 for pioneering vascular suturing technique. His most popular work is "Man-the Unknown' 